\title{
Giant Papilloma on the Back of the Knee Joint - A Case Report
}

\author{
M.V. Ravishankar' ${ }^{1}$ N.M. Shama Sundar², Pushpalatha K. ${ }^{3}$ \\ 1, 2, 3 Department of Anatomy, JSS Medical College, AHER, Mysuru, Karnataka, India.
}

\section{INTRODUCTION}

Papilloma is a benign tumour projecting above the surface of the skin. It grows from the epithelial tissue; develops as finger like fronds. Human contact with human papilloma virus (HPV) is one of the important causes for its occurrence. It feels rubbery and semisolid in consistency. Papilloma is a slow growing and long-lasting common tumor seen in various parts of the body like skin, breast, cervix, conjunctiva, etc. Its location on the exposed parts of the body like, around the face, neck, limbs, etc. causes much discomfort. Hence most of them prefer an early medical and surgical intervention to restore the cosmetic profile of the body to avoid growing physiopsychological discomforts. Clinical resemblance of any such swellings may require a meticulous examination and evaluation to differentiate them from other commonly seen external growths from the body surface; like sebaceous cyst, dermoid cyst, wart, haemangioma, neurofibroma, etc. One such clinical rare case of unusually large papilloma in an elderly lady aged about 65 years was presented with a swelling in her left popliteal region and excised under local anaesthesia, will be presented along with discussions.

Human body is prone to show some solitary or multiple swellings on the inner or outer surface of the body. For the clinical diagnosis of a swelling, it is important for a clinician to know its source of origin. Swellings may arise from the skin, subcutaneous tissue, muscle, vessel, nerve, bone, etc. It is also important to consider whether it is a congenital or acquired defect or it is caused due to any trauma, or could be a mere inflammatory response which lasts temporarily. ${ }^{1}$

An abnormal growth of cells which grow more rapidly than other normal cells in the body are called neoplasms. They may be benign (harmless) or malignant (cancerous). Benign swellings are usually localized, may grow big without spreading or invading into other structures whereas malignant swellings can spread and invade the nearby tissues directly or through the blood or lymph nodes to different organs through metastasis, hence they need a thorough clinical evaluation. Soft tissue swelling especially in the young individuals often may be missed or delayed in the diagnosis of malignancy due to asymptomatic nature of the lesion with unfamiliar age. The nature of the swelling, its duration, location, and tissue of origin also matters in the final diagnosis. Hence it is important to differentiate a benign swelling from a malignant swelling at the earliest. ${ }^{2}$
Corresponding Author: Dr. M. V. Ravishankar, Department of Anatomy, JSS Medical College, AHER, Mysuru, Karnataka, India. E-mail: ravishmvrs40@gmail.com

DOI: $10.14260 / j e m d s / 2021 / 515$

How to Cite This Article:

Ravishankar MV, Sundar NMS, Pushpalatha K. Giant papilloma on the back of the knee joint - a case report. J Evolution Med Dent Sci 2021;10(31):2517-2520, DOI: $10.14260 /$ jemds/2021/515

Submission 12-01-2021,

Peer Review 27-05-2021,

Acceptance 02-06-2021,

Published 02-08-2021.

Copyright (c) 2021 M. V. Ravishankar et al. This is an open access article distributed under Creative Commons Attribution License [Attribution 4.0 International (CC BY 4.0)] 


\section{PRESENTATION OF CASE}

A female patient aged around 60 years from a lower socioeconomic background reported to our consultation clinic with history of a large swelling on the back of her left knee joint for 5 years. Due to constant friction on its dependent surface on the ground while squatting, the skin over the mass was gradually abraded and there was an ulcer and infection of the skin and the adjacent tissue, causing pain, inflammation, and fever since 3 - 4 days for which she was given a course of broad-spectrum antibiotics (trimethoprim / sulphamethoxazole) and anti-inflammatory drugs for a week, later the wound got healed completely. After 15 days, she approached us for her growing physical discomfort due to the mass. On physical examination the swelling was found to be painless, solid, and rubbery in consistency. The mass was present behind the knee joint; it was attached to the skin through $1 \mathrm{~cm}$ pedunculated stalk. Its dimensions were about 6 $\mathrm{cm}$. in diameter and $10 \mathrm{~cm}$ in length. Skin over the swelling was normal with a healed scar tissue. There were no features of cystic consistency or moulding sign. Temperature was normal on the surface of the swelling. On examination it was confirmed that it was a case of papilloma; papilloma is a benign tumour arising from the skin or mucous membrane. Later she was advised to undergo basic blood investigations like $\mathrm{Hb} \%$, BT, CT, RBS, to confirm the fitness for surgery. Laboratory reports were within normal limits. (Hb 10.5 gms / dL, BT: 5' 30", CT: 4' 15", RBS: $125 \mathrm{mg} / 100 \mathrm{ml}$ ). Consent obtained from the patient.

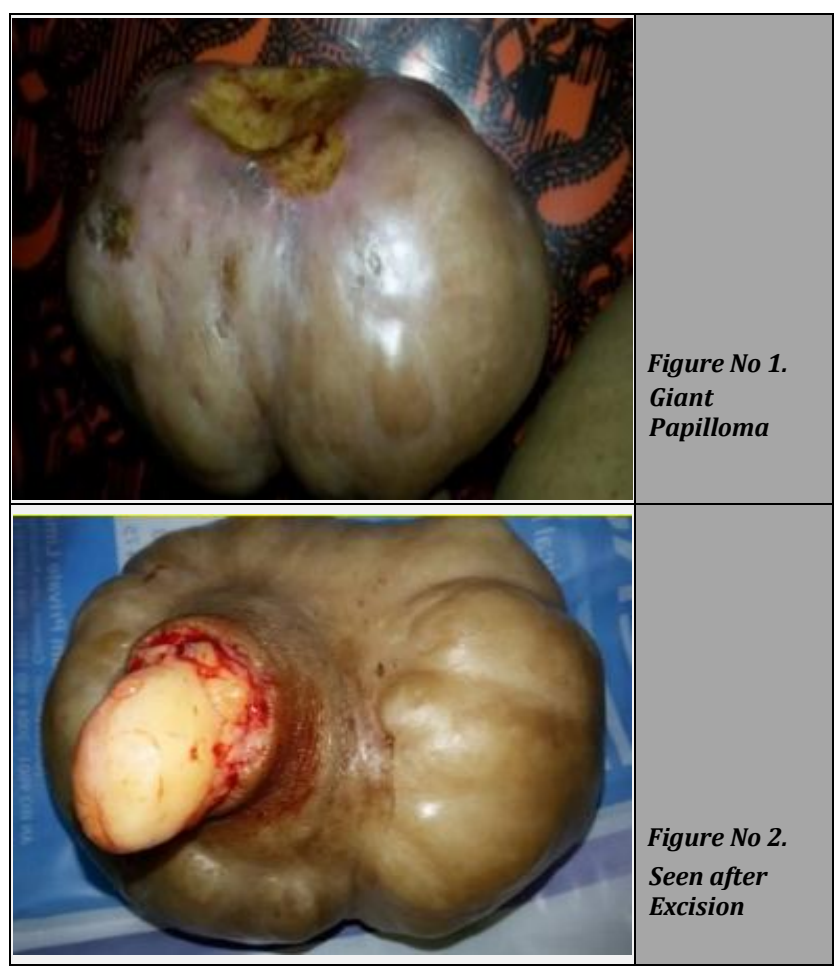

\section{DISCUSSION OF MANAGEMENT}

\section{Surgical Management}

With all aseptic precautions, under $3 \mathrm{ml}$ of local anaesthesia (2 $\%$ lignocaine with adrenaline) $1 \mathrm{~cm}$ incision was made around the base of the peduncle. Careful dissection separated the fatty tissue inside the tumour from the subcutaneous tissue of the popliteal region. Wound was closed after securing complete haemostasis using 3 - 0 black silk suture followed by dressing. Post operatively, a course of capsule amoxycillin $500 \mathrm{mg}$ twice daily with tablet ibuprofen $400 \mathrm{mg}$ thrice daily was given for a week. Sutures were removed after a week and the wound was clean and healthy, patient was followed up every month for 4 months, there was no immediate or delayed postoperative complications. The biopsy specimen was sent for histopathological examination. The report showed the content to be fatty tissue. An excision biopsy was taken, and it was subjected to $\mathrm{H} \& \mathrm{E}$ staining, and confirmed the same.

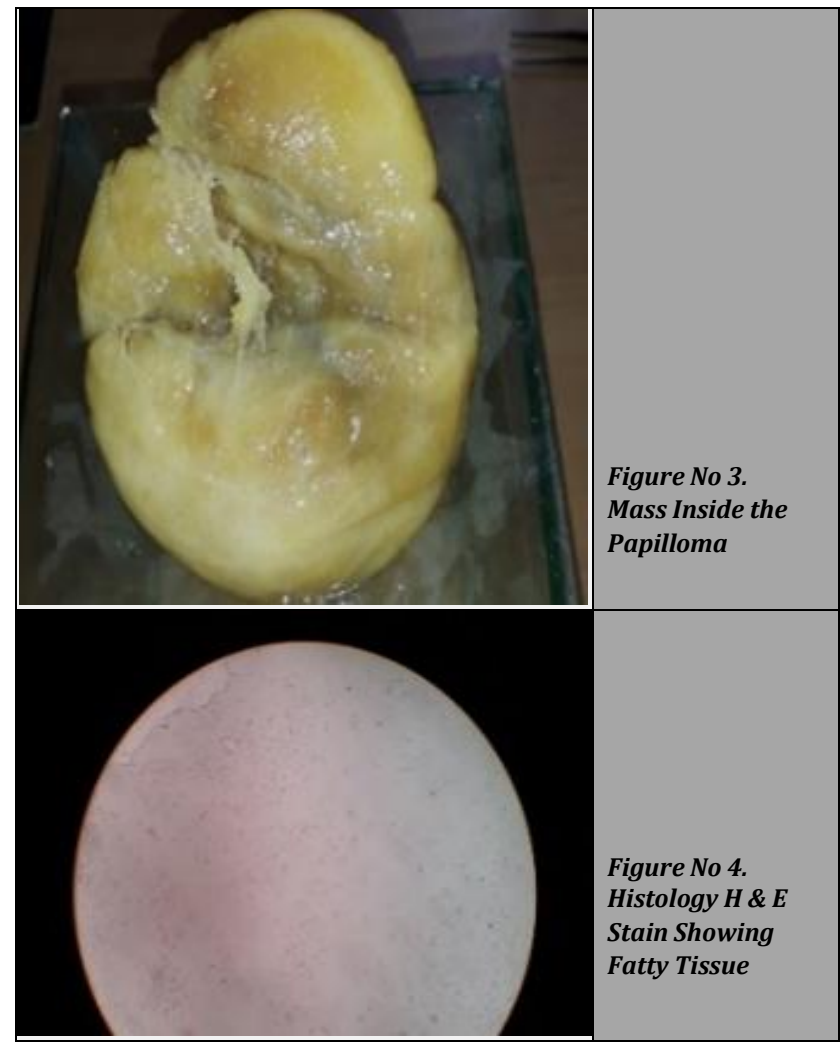

\section{DISCUSSION}

When a patient comes with a sign of swelling (tumour) on the body, physician needs to consider many such closely resembling clinical conditions for diagnosis. There are many conditions which are presented with the sign of swelling / tumour like growth over the body surface, some of them may closely resemble a lipoma, dermoid cyst, wart, haematoma, chronic abscess, haemangioma, neurofibroma, etc. Unfamiliarity of diversity of different types of swellings / tumours may lead to misdiagnosis and mismanagement.

Lipomas are adipose tumours; They are commonly seen subcutaneous mass of fat cells. Embryologically they are mesenchymal in origin. They are usually capsulated, lie beneath the skin and adherent to the underlying tissue which moves along with the skin. They are cluster of fat cells, and over activity of adipocytes produce a diffuse swelling. Sometimes a non-capsulated lipoma percolates into the muscle tissue called infiltrating lipoma. There are number of cytogenetic changes that have been attributed to the incidence of lipoma. Many individuals are prone to lipoma during their 
lifetime hence these swellings are known as "Universal Tumours". Lipoma can occur in different parts of the body; the degree of discomfort depends on its size and location; its size may range from few millimetres to few centimetres. Very rarely its unusual location like the plantar aspect of the foot is reported. ${ }^{3,4}$ The clinical presentations and diagnosis of a giant lipoma sometimes pose a challenge when it closely resembles with other benign or malignant tumours in the body. Liposarcoma is one such type of rare malignant tumour of mesenchymal origin, showing cancerous changes in the fat cells. It is commonly presented over the extremities and retroperitoneal regions. Hence while dealing with huge lipoma tumours it is essential to rule out the condition liposarcoma which is mostly seen in adulthood. ${ }^{5} \mathrm{~A}$ cystic swelling is a closed sac like structure, which contains solid, semisolid, liquid, or gaseous contents. It is developed if there is any blockade or damage to the drainage duct system of glandular secretions; usually these swellings are not painful. The dermoid cystic swelling malformations are classified into epidermoid, dermoid and teratoid cysts, which are lined with squamous epithelium. The epidermoid cyst lined by stratified squamous epithelium; dermoid cyst contains skin appendages called adnexa (hair, nail). A teratoma is a germ cell tumour, it contains well-differentiated tissues developed from three different germ cell layers like, ectoderm, mesoderm and endoderm.6,7 Sebaceous cysts are also known as epidermoid cysts; they are common benign encapsulated subepidermal nodules with restricted diffusion. They are derived from follicular infundibulum; they are usually filled with sebum a yellow cheesy material; which is usually presented with the central punctum on its surface. It is fixed to the skin and shows elevations, and it is moveable over the deep underlying structures along with the skin. ${ }^{8}$ Warts are fleshy bumps on the skin; they are called as verruca vulgaris, they are a type of benign swelling seen during any age. Usually they are caused by human papilloma virus (HPV), which is a transmitted by direct and indirect contact. HPV usually infects the keratinocytes resulting in the development of epidermal thickening with keratinization causing warts. ${ }^{9}$ Neurofibromas are group of genetic disorders, characterized by soft lobulated swellings, they are felt beneath the skin, usually associated with nervous tissue. Sometimes they arise form nerve bundles called plexiform neurofibroma. They are usually benign tumours seen in population with genetic tendency called neurofibromatosis type I (Von Recklinghausen's disease) which is a commonly seen clinical condition. ${ }^{10}$ Haemangiomas are heterogeneous, non-cancerous commonest benign vascular malformations, due to the proliferation of angioblast cells, that grow over a period. They are seen commonly during infancy and childhood; they grow rapidly but may undergo slow involution. Most of the time they remain docile, rarely bleed and cause the ulceration. The superficial haemangiomas arise from superficial dermis or deep haemangiomas arise from the deep dermis of the skin. Capillary haemangiomas are containing capillaries, which are lined with single layer of endothelial cells. Another type of haemangioma known as cavernous haemangioma consists of dermal tangles with large thin walled vessels surrounded by connective tissues. ${ }^{11,12}$ Papilloma is a benign tumour arising from the skin or mucous membrane. Some of the small cutaneous papillomas may undergo regression with time. The long standing and growing papillomas require surgical excision, which is one of the main lines of treatment. But some of the papilloma's can be removed by a non-surgical approach through cryotherapy, which is said to be an effective treatment which can prevent and reduce its recurrence. ${ }^{13}$

An infection with the human papilloma associated epithelial cyst seen with the consistent microscopic features of human papilloma virus infection. Though they were seen commonly in the palmoplantar regions, they were also seen in other regions like scalp, face neck, arm, leg, ${ }^{14}$ etc. Human papilloma infections on the skin or mucosa may be subclinical or latent, they are ubiquitous and are capable to adopt to the host.15 Skin related human papilloma virus is strongly associated with the extensive sun exposure at the biopsy site, could be a precipitating factor for papilloma formation. ${ }^{16}$

\section{CONCLUSIONS}

There are many cases seen as epithelial tissue outgrowths of skin, which are having features like swelling sign on the body surface. Papillomas are tumours that are required to differentiate from other commonly seen swellings on the body. Usually found on exposed parts of the body; before they turn into a giant swelling which needs to be handled on the grounds of its cosmetic concern preferred by an individual. Hence any tumour requires proper evaluation, and simultaneously needs to be handled through the early surgical interventions by creating a minimum scar especially on the exposed body parts.

Financial or other competing interests: None.

Disclosure forms provided by the authors are available with the full text of this article at jemds.com.

\section{REFERENCES}

[1] Das S. A Manual of Clinical Surgery. 10 th edn. Kolkata: S. Das Publication 2013: p. 47-50.

[2] Schaefers J, Vervloessem D, De Roover D, et al. Soft tissue swelling in children: case report, differential diagnosis and diagnostic delay. Clin Case Rep 2016;4(7):643-6.

[3] Prajapati DK, Mahajan S, Prajapati JM. Lipoma, the universal tumor: in a rare location. Int Surg J 2017;4(10):3542-5.

[4] Mctighe S, Chernev I. Intramuscular lipoma: a review of the literature. Orthop Rev (Pavia) 2014;6(4):5618.

[5] Inoue K, Higaki Y, Yoshida H. Giant retroperitoneal liposarcoma. Int J Urol 2005;12(2):220-2.

[6] Jham BC, Duraes GV, Jham AC, et al. Epidermoid cyst of the floor of the mouth: a case report. J Can Dent Assoc 2007;73(6):525-8.

[7] Sherpa P, Baral R. A clinicopathological evaluation of 230 cases of mature cystic teratomas. Nepal Journal of Obstetrics and Gynaecology 2016;11(1):51-3.

[8] Hoang VT, Nquyen CH, Chansomphou V, et al. Overview of epidermoid cyst. Eur J Radiol Open 2019;6:291-301.

[9] Chen SL, Tsao YP, Lee JW, et al. Characterization and analysis of human papillomaviruses of skin warts. Arch Dermatol Res 1993;285(8):460-5.

[10] Ghalayani P, Saberi Z, Sardari F. Neurofibromatosis type I (von Recklinghausen's disease): a family case report and literature review. Dent Res J (Isfahan) 2012;9(4):483-8. 
[11] Richter GT, Friedman AB. Hemangiomas and vascular malformations: current theory and management. Int J Pediatr 2012;2012:645678.

[12] Dilsiz A, Aydin T, Gursan N. Capillary hemangioma as a rare benign tumor of the oral cavity: a case report. Cases J 2009;2:8622.

[13] Huang YM, Huang YY, Yang HY, et al. Conjunctival papilloma: clinical features, outcome and factors related to recurrence. Taiwan J Ophthalmol 2018;8(1):15-8.

[14] Pusiol T, Piscioli F, Zorzi MG. Squamous cell carcinoma arising from human papillomavirus associated cyst. The
American Journal of Dermatopathology 2011:33(1):1056.

[15] Cubie HA. Diseases associated with human papillomavirus infection. Virology 2013;445(1-2):21-34.

[16] Forslund O, Iftner T, Andersson K, et al. Cutaneous human papillomaviruses found in sun-exposed skin: betapapillomavirus species 2 predominates in squamous cell carcinoma. The Journal of Infectious Diseases 2007;196(6):876-83. 